\title{
A JUDICIALIZAÇÃO DAS POLÍTICAS PÚBLICAS DESTINADAS AO CONTROLE DA POLUIÇÃO SONORA
}

\author{
THE JUDICIALIZATION PUBLIC POLICIES AIMED \\ TO CONTROL OF NOISE
}

\author{
${ }^{1}$ Marcia Andrea Bühring \\ ${ }^{2}$ Marcelo Segala Constante
}

\section{RESUMO}

O crime poluição sonora não está merecendo a atenção devida dos Tribunais de Justiça do Rio Grande do Sul. Pode-se observar que a legislação que tem por objetivo coibir este tipo de ofensa ao meio ambiente não está sendo aplicada da maneira que deveria, visto existir decisões mergulhadas nas teorias criticadas por Ovídio Baptista, sobre o processo de subsunção de um "caso" na regra, e de Klaus Bosselmann, onde a degradação ambiental só é relevante se causar grave dano, restringindo-se à penalização de direitos individuais, por ser dificultosa a identificação da degradação quando esta atinge a coletividade.

Palavras-Chave: Direito ambiental. Poluição sonora. Judicialização. Degradação ambiental. Qualidade ambiental.

\begin{abstract}
The noise pollution crime is not deserving due attention of the Courts of Justice of Rio Grande do Sul . It can be observed that the legislation aims to curb this type of offense to the environment it is not being applied the way it should, since there decisions steeped in the theories criticized by Ovid Baptista on the process of subsumption of a "case" in the rule, and Klaus Bosselmann where environmental degradation is relevant only cause serious damage, restricted to the penalization of individual rights, being labored to identify the degradation when it reaches the community.
\end{abstract}

Keywords: Environmental law. Noise pollution. Judicialization. Ambiental degradation. Environmental Quality.

\footnotetext{
${ }^{1}$ Doutora pela Pontifícia Universidade Católica do Rio Grande do Sul - PUCRS, Rio Grande do Sul (Brasil). Professora da Pontifícia Universidade Católica do Rio Grande do Sul - PUCRS, Rio Grande do Sul (Brasil). Advogada e Parecerista. E-mail: marcia.buhring@pucrs.br

${ }^{2}$ Mestrando em Direito Ambiental pela Universidade de Caxias do Sul - UCS, Rio Grande do Sul (Brasil). Graduado em Direito pela Universidade de Caxias do Sul - UCS, Rio Grande do Sul (Brasil).

E-mail: capconstante@gmail.com
} 


\section{INTRODUÇÃO}

Diversos são os instrumentos trazidos pelo direito que buscam minimizar ao máximo os danos contra o Meio Ambiente e propiciar a sua efetiva proteção, de forma a encontrar a harmonia entre o seu uso e a necessidade da sua preservação para as gerações futuras.

No Brasil, a Constituição Federal de 1988 estabelece que todos tem direito à um meio ambiente ecologicamente equilibrado, impondo-se não somente ao Poder Público a sua defesa e preservação, mas também à coletividade.

O objetivo da Constituição pode ser examinado sob diversos ângulos quando se trata em defesa e preservação do Meio Ambiente, seja pela ação do Poder Público em adoção de políticas públicas, seja pelo controle de emissão de poluentes no ar e nas águas, seja pelo regramento de condutas para certos tipos de atividades agrícolas, seja através da aplicação de punições a quem descumprir as normas de proteção do Meio Ambiente, e no rol de entes que devem buscar a defesa e proteção do Meio Ambiente está inserido o Poder Judiciário.

Porém, quando se trata de Poluição Sonora, fica evidente a dificuldade de se combater tal tipo de poluição, já que na esfera judicial, os juízes possuem entendimento que vai em detrimento da proteção da coletividade.

Não se discute que a poluição sonora está cada vez mais presente da vida em sociedade, aumentando na medida em que existe o progresso com a evolução científica e com a globalização, se tornando cada vez mais ofensiva para a saúde do homem.

Destaca-se como efeito de ruídos indesejados problemas de audição, distúrbios nervosos levando ao aumento da pressão arterial, distúrbio de sono, dentre outros. A própria Organização Mundial da Saúde destaca como a poluição sonora como um problema que causa danos à saúde, afirmando que $10 \%$ da população está exposta a ruídos em níveis que são danosos à saúde.

A Lei $n^{\circ}$ 6.938, de 31 de agosto de 1981, nos trás as diretrizes da Política Nacional do Meio Ambiente, por sua vez, e indica o conceito de poluição, porém é a Lei dos Crimes Ambientais, $n^{\circ} 9.605$ de 12 de fevereiro de 1968, que fixa uma punição para condutas lesivas ao Meio Ambiente. 
Nesse ínterim, cujo Meio Ambiente ecologicamente equilibrado possui status de direito fundamental, a busca pela sua preservação não pode ser resumida somente à previsão de restrições de condutas e das respectivas penas.

É necessário também que, após o devido processo legal, seja aplicada a devida penalidade ao autor do crime previsto na lei.

De nada adianta existir leis, resoluções e normas técnicas se tais não são aplicadas das maneiras que deveriam. E para compreender o que se propõem neste artigo, analisar-se-á que os casos submetidos ao judiciário restritos a formas menos graves de danos à saúde ou ao meio ambiente, exemplificando-se através da a poluição sonora, estão sendo decididas de forma errônea, não sendo destinadas a devida atenção.

Pelo fato de que o dano à saúde não é identificada facilmente ou até mesmo medida, como em danos ambientais mais graves que atentam contra a vida ou a propriedade, o crime de poluição sonora está sendo deixada de lado, como se fosse uma conduta natural.

Neste sentido o Tribunal de Justiça Gaúcho, ruma para o não reconhecimento do crime de poluição sonora. O motivo que mais se observa, e que não está de acordo com o objetivo da lei é, a não existência da prova do dano à saúde humana nos autos.

Existe jurisprudência que, desconsiderando totalmente o que diz as leis e resoluções que tratam do Meio Ambiente, bem como seus objetivos, consideram ruídos na medida de 89,6 decibéis como inofensivos à saúde humana.

Importante lembrar que as resoluções que complementam as legislações infraconstitucionais e que tratam do tema são específicas, mostrando que medida de ruídos é capaz de prejudicar a saúde humana, fato não apreciado pelos juízes.

Por outro lado, verifica-se jurisprudências que são aplicadas dentro de uma regra de julgamentos, ou seja, independente do que se apresenta no processo, o resultado negativo quanto a existência do crime já é certo.

Os juízes não estão dando a devida atenção às causas, mas sim cada vez mais inserindo essas causas nas regras de entendimento que seguem a mesma linha, causando prejuízo à defesa e proteção do meio ambiente equilibrado.

O fato do não reconhecimento do dano ambiental citado neste texto, será abordado a partir da explanação crítica de dois autores, que mostram que as decisões judiciais estão caminhando para um sentido oposto do qual o poder judiciário é incumbido, mergulhadas em questões procedimentais judiciárias editadas na maneira incorreta. 


\section{POLUIÇÃO SONORA: LEGISLAÇÃO PERTINENTE E IMPORTÂNCIA PARA A SAÚDE.}

A vida humana é consequência do meio ambiente. A existência da vida humana bem como a nossa qualidade de vida está diretamente condicionada à qualidade do meio ambiente. Nesse ínterim, a forma de utilização do meio ambiente pelos seres humanos é o termômetro que vai medir a sua existência ou não.

E é nesse contexto de semelhança que se verifica que a existência do meio ambiente depende dos seres humanos, e a existência dos seres humanos depende do meio ambiente. É uma lógica muito simples de se entender.

Não se pode olvidar que a discussão sobre questões relativas ao Meio Ambiente não são recentes. José Eli da Veiga explica que existe a busca do meio ambiente sustentável desde a necessidade de diferenciação de desenvolvimento e crescimento econômico. (VEIGA, 2000, p. 18)

Sirvinskas aponta a importância da preservação do Meio Ambiente para a vida dos seres humanos realizando um contexto histórico da sua existência, onde os povos da antiguidade já começavam a valorizar as terras que eram banhadas por rios, pois com o transbordo, o húmus adubavam as margens, tornando-as mais férteis para a plantação. (SIRVINSKAS, 2009)

José Rubens afirma que a preservação ambiental é de fato, a proclamação de um direito fundamental intergeracional de participação solidária. (LEITE, 2000, p. 95)

É cristalino que o Meio Ambiente ecologicamente equilibrado é direito fundamental devidamente previsto na Constituição Federal.

O meio ambiente precisa ser preservado sob pena de extinção da existência do homem. É essa preocupação que enseja a implementação de regras de conduta sobre a utilização do meio ambiente. Desde a Declaração de Estocolmo se enfatiza a necessidade de ser medida a utilização dos ecossistemas até o limite em que seja possível para que as próximas gerações possam usufruir deste direito fundamental da mesma maneira que se desfruta hoje.

É histórico que, a utilização dos recursos naturais estão até hoje, infelizmente, ligados à economia. José Eli da Veiga deixa essa circunstancia muito clara, porém este doutrinador enfatiza na obra "Desenvolvimento Sustentável: o desafio do século XXI" que antigamente, a 
utilização destes recursos tendo em vista o crescimento econômico era mais gritante. Era a economia que ditava as regras para a utilização do meio ambiente. (VEIGA, 2000)

Adir Rech explica com maestria que a economia não é nem mesmo um direito fundamental, mas sim um instrumento de produção de bens e riquezas, por isso não se pode coloca-la em primeiro plano, antes do Meio Ambiente. (RECH, 2012)

Porém, apesar de ainda existir influência da economia na utilização dos recursos naturais, esta influencia já é analisada com outros olhos. Certamente os olhos da razão.

Não é a toa o reconhecimento do Meio Ambiente como direito fundamental e a previsão na Constituição Federal do direito à um meio ambiente equilibrado, dever do estado e da coletividade a sua defesa e preservação.

José Afonso da Silva diz que:

“a qualidade do meio ambiente se transforma num bem, num patrimônio, num valor mesmo, cuja preservação, recuperação e revitalização se tornaram num imperativo do Poder Público, para assegurar a saúde, o bem-estar do homem e as condições de seu desenvolvimento. Em verdade, para assegurar o direito fundamental à vida. (SILVA, 2012, p. 851)

José Eli da Veiga aponta que a medição do uso do meio ambiente para encontrarmos a sustentabilidade ainda é uma utopia, porém os estudos que levam a adoção de um caminho razoável devem existir. (VEIGA, 2000, p. 208)

E estes estudos onde se encontra limites para certas condutas que afetam o meio ambiente equilibrado, irão refletir na aplicação dos textos legais.

A lei 6.938, promulgada em 31 de agosto de 1981, que tem como objeto o regramento do uso do meio ambiente, trás conceitos e definições importantes. Porém, o que se chama atenção é que, nesta Lei da Política Nacional do Meio Ambiente é que se encontra as definições legais do que é entendido como degradação da qualidade ambiental e poluição.

Sirvinskas explica que, depois da Constituição Federal, a Lei 6.938 é a lei mais importante no que tange à proteção do meio ambiente, visando dar efetividade ao princípio matriz contido no art. 225, caput, da Constituição Federal. (SIRVINSKAS, 2009, p. 133)

No inciso I do artigo $9^{\circ}$ da Lei 6.938, observa-se que um dos instrumentos da política nacional do meio ambiente é o estabelecimento de padrões de qualidade ambiental (normas baixadas pelo CONAMA). 
Os critérios estabelecidos nos padrões de qualidade são estabelecidos por meio de pesquisas e análises de qualidade ambiental. Trata-se de uma necessidade imprescindível para as atividades do homem com a sustentabilidade, sendo os padrões de qualidade divididos em: padrões de qualidade do ar, das águas e para ruídos no meio ambiente. (SIRVINSAS, 2009, p. 142)

A qualidade ambiental da qual será estabelecido os padrões pelas normas baixadas pelo CONAMA, é a mesma qualidade ambiental citada na alínea "a", inciso III do artigo $3^{\circ}$ da Lei 6.938, onde a lei que referir que a degradação da qualidade ambiental é POLUIÇÃO. Ou seja, o conceito de poluição está ligada à degradação da qualidade ambiental, esta que terá os padrões estabelecidos pelo CONAMA.

A Resolução 01 do CONANA, Conselho Nacional do Meio Ambiente, cuidou de regular os padrões de emissão de ruídos de qualquer atividade industrial, comercial, social ou recreativa. Trata-se de regular a poluição sonora.

A NBR 10.151, por sua vez, norma editada pela Associação Brasileira de Normas Técnicas em 2000.

Importante referir que, a Resolução 01 do Conama, no inciso II, trás explícito que são prejudiciais à saúde e ao sossego público, os ruídos com nível superior aos considerados aceitáveis pela NBR - 10.151, que por sua vez, trás as seguintes informações, conforme o tipo de área e o período do dia:

\begin{tabular}{|l|c|c|}
\hline TIPOS DE ÁREAS & DIURNO & NOTURNO \\
\hline Áreas de sítios e fazendas & 40 & 35 \\
\hline $\begin{array}{l}\text { Área estritamente residencial, urbana, de } \\
\text { hospitais ou de escolas }\end{array}$ & 50 & 45 \\
\hline Área mista, predominantemente residencial & 55 & 50 \\
\hline $\begin{array}{l}\text { Área mista, com vocação comercial e } \\
\text { administrativo }\end{array}$ & 65 & 60 \\
\hline Área mista, com vocação recreacional & 65 & 55 \\
\hline Área predominantemente industrial & 70 & 60 \\
\hline
\end{tabular}

Os limites trazidos em decibéis (unidade utilizada para medição de ruídos) presentes na tabela acima é de fácil análise e interpretação.

Certamente os estudos que cuidaram de analisar os níveis de ruídos que são produzidos foram necessários foram necessários graças à poluição sonora cada vez mais presente no dia-a- 
dia dos cidadãos, conforme se observa no rol de considerações da Resolução 01/90 do CONAMA.

Nesse ínterim, não se pode tratar a poluição sonora como uma simples causa ou consequência da globalização ou da evolução da tecnologia no meio social, e sim como um problema generalizado que deve ser estancado, por isso a necessidade de regulamentação de níveis de poluição sonora.

Nesta linha que seguiu a legislação brasileira. A Lei dos Crimes Ambientais, promulgada em 12 de fevereiro de 1998, veio a fortalecer a proteção do Meio Ambiente, inclusiva pela previsão de penas, incluindo-se a prisão.

A determinação de condutas com a cominação de sanções é fundamental para a efetiva defesa do meio ambiente equilibrado, porém, é importante que as sanções sejam devidamente aplicadas à quem descumprir a lei penal ambiental.

Luigi Ferrajoli já explicava:

O direito é uma construção humana e pode gerar ele mesmo condições e critérios de
justificação das decisões por ele admitidas como válidas. Precisamente, o direito é um
universo linguístico artificial que pode permitir, graças à estipulação e à observância
de técnicas apropriadas de formulação e de aplicação das leis aos fatos julgados, a
fundamentação dos juízos em decisões sobre a verdade, convalidáveis ou invalidáveis
como tais, mediante controles lógicos e empíricos e, portanto, o mais possível
subtraídas ao erro e ao arbítrio. (FERRAJOLI, 2010, p. 71)

O que se percebe no Tribunal de Justiça do Rio Grande do Sul é a inaplicabilidade da sanção do crime de poluição sonora pelo fato de que não está presente no processo a menção ou a identificação ao dano à saúde.

É necessário falar mais sobre o efetivo dano à saúde produzido pela poluição sonora do que está escrito na Resolução 01 do CONAMA e na NBR 10.151?

É notório que qualquer produção de ruídos inoportuno prejudica a concentração do estudante, a recuperação do doente, o descanso do trabalhador, a aula do professor. Porém, para deixar claro que certos níveis de produção de ruído são realmente prejudiciais à saúde, tal fato foi devidamente regulamentado.

A partir deste ponto nevrálgico, é importante traçar alguns comentários. 


\title{
2. A ABRANGÊNCIA DAS DECISÕES JUDICIAIS NO DO TRIBUNAL GAÚCHO SOBRE OS DANOS À SAÚdE HUMANA CONSEQUENTES DA POLUIÇÃO SONORA.
}

Para apresentar um breve retrato da evolução da poluição sonora, pertinente analisar a passagem de Ivan Izquerdo na obra "Silêncio, por favor."

\begin{abstract}
Há muito mais barulho hoje no mundo do que antigamente, porque o número de habitantes do planeta é cada vez maior e porque as máquinas que fomos inventando no último século não funcionam sem produzir ruídos. Há menos de 90 anos, quem desejasse ouvir música tinha que se dirigir ao lugar onde era executada: nas salas de concertos, nos palácios, nas praças públicas ou nas casas onde moravam aqueles que a executavam. O disco, primeiro, e o rádio, depois, permitiram a música à domicílio, o seu transporte até o ouvinte, em vez de deslocar o ouvinte até o local onde a musica é produzida. Hoje, os amplificadores se encarregam de levá-la até os ouvidos daqueles que não a querem ouvir. Um carro que passa lentamente frente à nossa janela, no meio da madrugada, pode nos acordar com o forró proveniente de seu podersoso equipamento de som. Os amplificadores de um clube noturno podem atrapalhar o sono dos moradores de todo um bairro ou impedí-los de apreciar algum outro tipo de música do seu agrado. (IZQUIERDO, 2010, p. 12)
\end{abstract}

Rogério Paniago Carvalho, arquiteto que possui muito afinidade com a acústica, diferencia "som" de "ruído", conceituando este como toda vibração ou onda mecânica gerada por um corpo vibrante, passível de ser detectada pelo ouvido humano, e aquele como "todo som indesejável”. (CARVALHO, 2010, p.12)

Além disso, o arquiteto deixa claro na sua obra literária que:

Já há muito, desde a segunda metade do século passado, vêm sendo feitos estudos e publicados artigos em nível internacional, incentivados pela Organização Mundial da Saúde, sobre questões de ruídos e seus efeitos sobre o homem.

Médicos, fonoaudiólogos e outros especialistas já dispõem de bibliografia extensa sobre os malefícios causados por esse subproduto do progresso, tais como:

- perda parcial (e até mesmo total) da audição;

- problemas gastrointestinais e cardiovasculares decorrentes das sucessivas contrações musculares;

- problemas respiratórios e de secreções hormonais; e o mais inquietante; 


\begin{abstract}
- distúrbios no sistema nervoso é o que mais sofre com as agressões sonoras: o sistema nervoso simpático ao excitado enrijece os órgãos que ele governa, induzindo ao aumento da pressão arterial, por exemplo. (CARVALHO, 2010, 42)
\end{abstract}

A Lei da Política Nacional do Meio Ambiente, bem como a Lei dos Crimes Ambientais se mostram como políticas públicas eficientes em combater a poluição sonora.

Porém, foi com a Resolução 01/90 do CONAMA que colocou-se em prática um dos instrumentos da lei de políticas ambientais, que culminou na edição NBR 10.151. Nesta NBR, realizou-se pesquisas e análises do fenômeno que é a propagação de ruídos, e estabeleceu limites através de níveis de ruídos permitidos.

Considera-se que o problema poluição sonora, assim, esta cercada de mecanismos eficientes e eficazes sobre o seu controle.

Porém, frisa-se que, para a efetividade das políticas públicas para controle da poluição sonora, de nada basta a existência de normas regulamentadoras, estabelecimentos de limites, regramento de condutas com as consequentes sanções, se no momento da aplicação destas penas os juízes aplicarem as normas em desconformidade com a finalidade para a qual foram editadas.

Infelizmente, é isso que se observa no Rio Grande do Sul. Ao realizar pesquisa de jurisprudência no Tribunal de Justiça deste Estado percebe-se que o entendimento dos juízes que atuam na esfera penal anda na contramão da finalidade das políticas públicas adotadas sobre a poluição sonora, que é controlar a emissão de ruídos.

Cita-se inicialmente a argumentação ilógica e incoerente contida na decisão da apelação julgada pela Turma Recursal Criminal dos Juizados Especiais Criminais do Estado do Rio Grande do Sul, Processo n $71005569488^{3}$.

O julgador considerou a medida de 89,6 decibéis como inofensivo à saúde do homem quando afirma que não há prova da "possibilidade" de ocorrer o dano, inexistindo indicativos de que a medição aferida tenha o condão de causar risco a outrem.

De imediato surge a questão: como pode magistrado entender não haver dano à saúde humana nos casos de poluição sonora produzida a um nível de 89,6 decibéis, independente da prova estar ou não presente nos autos, se a Resolução $n^{\circ} 01$ do Conama é taxativa ao referir que

\footnotetext{
${ }^{3}$ In Verbis: Para caracterização do tipo penal do art. 54 da Lei no 9.605/98, não é qualquer poluição que se amolda à figura típica, sendo necessária que seja em níveis tais que resultem ou possam resultar danos à saúde humana, ou que provoque a mortandade de animais ou a destruição significativa da flora.

Entendo que, para configuração do tipo penal em apreço, não basta que o ruído esteja em desconformidade com a lei local, pois a hipótese caracterizaria mera infração administrativa. É imprescindível que o nível do som tenha potencialidade de causar dano, o que, no caso concreto, não se verificou.
} 
“são prejudiciais à saúde e ao sossego público, os ruídos com nível superior aos considerados aceitáveis pela NBR - 10.151."

É essa a visão no Tribunal de Justiça do Rio Grande do Sul.

APELAÇÃO CRIME. MATÉRIA AMBIENTAL. ART. 54, § 1º, DA LEI No 9.605/98. POLUIÇÃO SONORA. Inexistência de prova a respeito da potencialidade sonora e do tempo de emissão como agentes aptos a causar danos à saúde humana. Decisão absolutória mantida. (Apelação crime $\mathbf{n}^{\mathbf{0}} \mathbf{7 1 0 0 5 2 0 7 2 0 4}$, Turma Recursal Criminal, Tribunal de Justiça do Rio Grande do Sul, Relator: DR. Edson Jorge Cechet. Julgado em 26/01/2015. Acessado em 12/05/2016.)

Outras decisões seguem o mesmo sentido:

HABEAS CORPUS. CRIME AMBIENTAL. PESSOA JURÍDICA. POLUIÇÃO SONORA. ART. 54, CAPUT, DA LEI No 9.605/98. FATO ATÍPICO. Cabimento do habeas corpus para proteção da pessoa jurídica, conforme precedente do Supremo Tribunal Federal, sob o argumento de que, no momento em que se a reconhece como ré (art. $225, \S 3^{\circ}$, da $\mathrm{CF}$ ), tem que dar-se a ela o direito à ação constitucional contra perpetração de ilegalidades.

A poluição sonora não se presta à conformação típica do art. 54, da Lei no 9.605/98, por não alcançar o bem jurídico nela tutelado, ou seja, os sons, os ruídos ou as vibrações, ainda que em níveis excessivos, porque não são capazes de causar alterações substanciais no meio ambiente. Entendimento desta Câmara. Deferido o trancamento da ação penal, nos termos do art. 386, inc. III, do CPP. ORDEM CONCEDIDA. (Apelação crime $\mathbf{n}^{\circ}$ 70056708431, Turma Recursal Criminal, Tribunal de Justiça do Rio Grande do Sul, Relator: DR. Edson Jorge Cechet. Julgado em 17/10/2013. Acessado em 12/05/2016.)

Nesse ínterim, Gunter Fellemberg, ensina exatamente o contrário:

Sons desagradáveis e indesejáveis já provocam neuroses com intensidades sonoras bem mais baixas (na ordem de $80 \mathrm{~dB}$ e menos), principalmente se a fonte sonora não puder ser eliminada e o indivíduo se sentir indefeso frente ao ruído (por exemplo, o piano do vizinho, gritos de criança, rádio em alto volume, o barulho do transito, etc.). ( FELLEMBERG, 2012, p. 190) 
É plenamente visível que o fenômeno poluição sonora não está merecendo a atenção que deveria por parte do Judiciário do Rio Grande do Sul, no que tange à sua criminalização.

$\mathrm{O}$ primeiro argumento levantado neste artigo para explicar esta antinomia entre decisões judiciárias e o objetivo das políticas públicas em regular a emissão de ruídos com vistas à proteger a saúde do homem é do autor Klaus Bosselmann que fala sobre a lógica reducionista do não reconhecimento de danos coletivos, somente dos individuais, e da dificuldade de identificar danos ambientais que não atinjam somente a vida e a propriedade, mas outros direitos como a saúde e o sossego.

É evidente que a poluição sonora atinge o direito coletivo tendo em vista ser um aspecto observado em espaços urbanos, onde os recebedores desta produção de ruídos são todas as pessoas que estão no entorno da fonte propagadora dos sons.

As ações judiciais penais, por sua vez, são motivadas na grande maioria das vezes por pela atuação dos Órgãos Fiscalizadores do Estado que através do Poder de Polícia realizam a inspeção e medição dos sons produzidos pelas suas fontes propagadoras e não pelas vítimas da poluição sonora.

Como esta poluição possui como vítima a coletividade, diferentemente de outros danos que atingem o indivíduo como a contaminação de uma represa que abastece uma cidade (que atingem determinada população), torna-se dificultosa a mensuração dos seus danos.

O dano à saúde provocado pela poluição sonora não é palpável ou visível tendo em vista que é a coletividade a atingida, sendo difícil a mensuração ou a quantificação do dano causado aos indivíduos. Já a contaminação da água de uma represa, o dano à saúde é visível e palpável, podendo ser atingido até mesmo o direito à vida, sendo as reações danosas imediatas e de fácil ligação com a sua causa.

Ainda, no caso da poluição sonora, a ação penal é na maioria das vezes iniciada pela atuação do Poder Público e não pela reclamação das pessoas vitimadas.

Por isso, como medir os danos causados às pessoas que moram a lado de um local de encontro de jovens que se reúnem para ouvir música em volume alto, casos comuns nos centros urbanos durante a noite, fazendo com que a vizinhança não se consiga dormir, assistir televisão, nem ao menos conversar dentro da sua residência.

Segundo as decisões dos juízes o poder fiscalizatório dos órgãos estatais que realizam as medições dos ruídos não é suficiente. Talvez seja necessária uma comprovação médica de que o aparelho auditivo antes do fato analisado era melhor do que depois do fato. Talvez seja 
necessário apresentar dois laudos médicos do antes e do depois do fato para serem analisados na decisão judicial.

Ora, é tendo em vista essa dificuldade de mensuração dos danos da poluição sonora, que as leis, resoluções e normas que tratam desta poluição estabelecem limites para a propagação de ruídos.

Explicando a influencia que o princípio da sustentabilidade está tendo sobre os direitos humanos e nosso pensamento sobre liberdade individual, Klaus Bosselmann faz uma alerta.

\footnotetext{
Mesmo onde grupos ambientalistas e outros que defendem interesses públicos sustentam que há violações de direitos de populações inteiras, o critério jurídico é o direito individual à vida ou à propriedade. Isso fomenta uma lógica reducionista, quase absurda: quanto maior é o número de pessoas ameaçadas, tanto menos prováveis são as violações de direitos humanos. (BOSSELMANN, 2012, p. 79)
}

Ou seja, a lógica reducionista explicitada por Bosselmann nos leva ao reconhecimento de violações de direito individuais á vida ou à propriedade, caso não que não se verifica na poluição sonora, que se busca o direito à tranquilidade, ao meio ambiente equilibrado e ao sossego, evitando danos à saúde.

Além disso, neste ponto nevrálgico, este autor explica que:

\footnotetext{
A jurisprudência neste sentido, tem ficado restrita a formas graves de poluição ambiental que tenham um impacto direto sobre direito de indivíduos. [...] Há uma interpretação restritiva sugerida quando consideramos violação a direitos humanos somente os efeitos ambientais imediatos sobre saúde e bem-estar humanos. A degradação ambiental só é relevante e coercitível na medida em que cause uma violação direta e grave de direitos de indivíduos. (BOSSELMANN, 2010, p. 84)
}

A poluição das águas de uma represa, não necessita de uma norma para medição da quantidade de produto químico que foi jogado em seu leito para que então seja reconhecido tal fato como crime. Basta que o indivíduo que bebeu desta água mostre que está com consequências em sua saúde.

Agora, como mostrar que o aparelho auditivo se alterou com a emissão de ruídos? Como provar que realmente existiu a impossibilidade de se dormir a noite? Como mensurar o grau de stress ou do distúrbio nervoso que um indivíduo vizinho à uma casa noturna sentiu quando tentava realizar um trabalho da faculdade e sentia quando ainda não existia ruído? 
Esta resposta é fácil. Com a medição dos ruídos pelos órgãos estatais, tendo em vista que os danos à saúde já estudados, pesquisados e comprovados através de estudos e pesquisas estão dispostos em normas devidamente previstas pela lei da Política Nacional do Meio Ambiente.

Por enquanto, percebe-se que a teoria de Bosselmann está presente nas decisões do judiciário, infelizmente.

\section{A SUBSUNÇÃO DE “CASOS” À REGRA NAS DECISÕES.}

Os juízes entendem que os processos judiciais no qual figura um autor do crime de poluição sonora devem ser arquivados, com da absolvição deste, pelo simples fato de não haver danos à saúde especificados no processo, como por exemplo, deficiência do aparelho auditivo.

Estas decisões, além de se identificar com o que diz Klaus Bosselmann, explicando a dificuldade de se reconhecer violações à direitos coletivos, também seguem a linha de raciocínio que o autor Ovídio Baptista critica obra "Epistemologia das Ciências Jurídicas Culturais".

Tendo em vista o número de demandas ao Poder Judiciário, e também ao número de causas com a mesma finalidade, o judiciário acaba inserindo casos parecidos em uma "regra" de decisão.

É o que explica o Dr. Ovídio Araújo Baptista da Silva:

Do juiz concebido como um ser inanimado, desligado de sua cultura, estamos hoje nas mãos de juízes que se tornaram arbitrários, por uma contingência inelutável. Como eles não foram preparados para fundamentar suas decisões - que o sistema, aliás, nem mesmo admite -, as infindáveis alternativas oferecidas por uma linguagem essencialmente pluriunívoca, permite-lhes julgar como querem.

Os tribunais e eles próprios limitam-se a "explicar" como descobriram a “vontade da lei”. Em geral, antes de comprometer-se com o julgamento, o juiz já preparou o "caso" de tal modo que dele fossem expurgados os fatos e circunstâncias que o emoldam. Isto permite-lhe subsumir o "caso" à regra, através do critério de subsunção, perante o qual a originária analogia que caracteriza a essência dos fatos reais, torna-se identidade. (SILVA, 2009, p. 124)

Ovídio (SILVA, 2009) esclarece que esta forma de julgar ocorre graças ao mais radical e injustificável centralismo no Poder Judiciário. Porém, as decisões em que simplesmente se 
deixa de observar a particularidade dos aspectos de cada processo causam, além da descrença nas normas, o pensamento de que se pode cometer tais delitos, ainda que devidamente proibidos na lei.

Quando se fala em poluição sonora, em âmbito judicial, antes de qualquer valoração de juízo do que consta nos autos, já existe o preconceito de que o crime de poluição sonora não causa danos à saúde, ou não causa danos ao meio ambiente.

É o caso do julgado:

CRIMES AMBIENTAIS. POLUIÇÃO SONORA. EQUIPAMENTOS DE SOM AUTOMOTIVO. ART 54, $\S 1^{\circ}$, DA LEI 9.605/98. ATIPICIDADE DA CONDUTA. Para a configuração do tipo penal em apreço não basta que o ruído esteja em desconformidade com a lei municipal; é imprescindível que o nível do ruído tenha potencialidade de causar dano, o que não se verificou no caso presente. Além disso, o art. 54 da Lei 9605/98 não contempla a poluição sonora decorrente do uso abusivo de equipamentos de som veiculares, referindo-se antes às atividades relacionadas ao meio ambiente. Conduta atípica. RECURSO IMPROVIDO. (Apelação crime $\mathbf{n}^{\mathbf{0}}$ 71005565510, Turma Recursal Criminal, Tribunal de Justiça do Rio Grande do Sul, Relator: DR. Luis Gustavo Zanella Piccinin. Julgado em 01/05/2016. Acessado em 12/05/2016.)

É visivelmente claro o critério de subsunção citado por Ovídio Baptista nos julgados acima citados. E por mais incrível que possa parecer, no julgado do Habeas Corpus (processo $\mathrm{n}^{\mathrm{o}}$ 70033430190), assim como em outros julgados, o Relator Aristides Pedroso, da Quarta Câmara Criminal frisa ao Ministério Público justifica que é entendimento desta Câmara, reiteradamente manifestado, inclusive em inúmeras ordens de habeas corpus em tudo iguais à presente, que o art. 54 da Lei n ${ }^{\circ}$ 9.605/98 diz respeito ao meio ambiente, não guardando relação com a poluição sonora decorrente de uso abusivo de instrumentos musicais.

Ora, o magistrado, muito provavelmente inclinado pelo critério da subsunção, chega a dizer que: "por entendimento da Câmara, o artigo 54 da lei 9.605 diz respeito ao meio ambiente, e não guarda relação com a "poluição sonora" decorrente do uso abusivo de instrumento musicais. É o exemplo claro do critério de subsunção, explicado por Ovídio Baptista.

Jeferson Dytz Marin explana sobre a postura comodista do judiciário de dizer o direito a partir do já dito: 
Ao simplificar algo complexo por natureza, à custa da substituição da fundamentação pela repetição, o direito acaba por adotar um viés massificador de produção hierática, tipicamente industrial. É o modelo fordista. A (des) consideração da coisa julgada e os verbetes estandardizantes subvertem a garantia constitucional da motivação das decisões judiciais (art. 93, IX, CF) já que prepostas pelo Tribunal. (MARIN, 2015, p. 52)

Não necessário uma interpretação mais apurada da letra da lei para entender que a poluição de qualquer natureza que venha a causar dano à saúde, é crime. Não há menção em parágrafos ou incisos de que a "poluição sonora" esteja fora do alcance do artigo 54 da lei os crimes ambientais.

Soma-se o fato da previsão da Lei da Política Nacional do Meio Ambiente conceituando poluição como degradação da qualidade ambiental que prejudiquem a saúde, dando respaldo para a resolução 01 de 1990 do CONAMA e para a NBR 10151.

Porém, observa-se que, pelo fato de já existir o entendimento do não reconhecimento do crime de poluição sonora, os argumentos dos juízes vão desde a alegação de não existir prova danos à saúde (mesmo admitindo que os níveis estão acima do regulado pela NBR 10151) chegando ao absurdo do não reconhecimento da poluição sonora como poluição.

Apesar da Resolução 01 de 1990 mencionar taxativamente que níveis acima do que estabelece a NBR 10151 causam danos à saúde, o entendimento dos juízes é o contrário.

Sábias palavras de Carlos Alberto Lunelli e Leonardo Augusto Poletto ao explicitarem o direito fundamental de proteção do meio ambiente no ordenamento jurídico brasileiro, enfatizando que, a atividade do Poder Judiciário não se exaure na simples e comum subsunção da lei aos fatos, o que pode levar aos excessos e surpresas da lógica formal aplicada ao direito ${ }^{4}$. (LUNELLI, POLETTO, 2011, p. 21)

Por sorte, ainda encontra-se poucas decisões neste sentido, como na Apelação Crime No 71002322238, da Quarta Câmara Criminal do Tribunal de Justiça do RS.

E, depositando nossas esperanças em julgados como este, somado ao trabalho árduo e longo de uma construção científica na busca de mudanças de que decisões e entendimentos não sejam genéricos e desatualizados do que ora se assiste, pode-se então mudar o cenário atual que é caótico.

\footnotetext{
${ }^{4}$ LUNELLI, Carlos Alberto. POLETTO, Leonardo Augusto. O Direito fundamental da proteção do meio ambiente no ordenamento jurídico brasileiro e o protagonismo do direito em matéria ambiental. LUNELLI, Carlos Alberto (coord). Direito, ambiente e políticas públicas. Curitiba: Juruá, 2011, p.21.
} 


\section{CONSIDERAÇÕES FINAIS}

A poluição sonora é um fenômeno cada vez mais presente na vida das pessoas, principalmente do meio urbano. A propagação de sons e ruídos é crescente devido diversos fatores como desenvolvimento tecnológico, globalização, necessidades de inserção em um grupo social, etc..

Porém, os danos provocados pela poluição sonora à saúde bem como o desequilíbrio do meio ambiente equilibrado é evidente.

Por isso e pelo fato de ser de difícil mensuração a ofensa a saúde, foi adotado como parâmetro a edição da Resolução 01 de 1990, como instrumento da Lei de Política Nacional do Meio Ambiente, que regulou através da BNR 10151 os limites de propagação de ruídos.

As políticas públicas com vistas ao controle da difusão desordenada da poluição sonora através da edição de normas são eficazes, porém não estão sendo efetivas.

Isso graças ao fato de não atentar contra o interesse individual e não se comparar com outros tipos de poluição capazes de atentar contra bens maiores como a vida a poluição sonora não está sendo encarada da maneira como deveria.

Ainda, destaca-se que o processo de subsunção de casos à regra está muito inserida nos julgamentos do judiciário do Rio Grande do Sul.

Assim ruma-se para o lado contrário ao que estabelece a Constituição Federal, quando é estabelecido que é um dever a defesa e a preservação do meio ambiente equilibrado.

Em que pese o judiciário assumir o papel de um defensor da executoriedade das leis, já que somente a existência destas não capaz de forçar o seu cumprimento, vê-se o judiciário assumir um papel contrário, qual seja de defensor dos autores de crime de poluição sonora.

Por sorte, ainda se encontra uma luz no fim do túnel, quando se observa pouquíssimas decisões judiciais, que submergidas no objetivo da lei, conseguem refletir o seu ideal, que é a preservação e a manutenção do Meio Ambiente Equlibrado, se despindo de critérios e teorias, ultrapassando as barreiras impostas pelo comodismo e pelas visões genéricas de que somente os danos graves contra a saúde devem ser reconhecidos como tal.

A luta pelo reconhecimento do crime de poluição sonora pelo Tribunal de Justiça do Rio Grande do Sul, é o que deve ser buscado, se não continuará o declínio da eficiência norma legal e a descrença da eficácia da legislação brasileira. 
Obviamente não se deve criminalizar todas as condutas para que não se incorra na banalização das leis penais. Porém, deve-se cumprir o que está vigente, aplicando as penas previstas, sob pena de incidirmos na ineficácia da lei penal e retrocedermos rumando para o lado contrário daquilo que os povos da antiguidade um dia descobriram e nos deixaram de herança: a importância do meio ambiente.

\section{REFERÊNCIAS}

ASSOCIAÇÃO BRASILEIRA DE NORMAS TÉCNICAS. NBR 10151. Acústica Avaliação do ruído em áreas habitadas, visando o conforto da comunidade Procedimento. Rio de Janeiro, 2000.

BRASIL, Lei 6.938 de 31 de agosto de 1981.

BRASIL, Lei 9.605 de 12 de fevereiro de 1998.

BRASIL, Constituição, 1988, Artigo 225.

BOSSELMANN, Klaus. Estado socioambiental e Direitos fundamentais. Porto Alegre: Livraria do Advogado Editora, 2010.

CARVALHO, Rogerio Paniago. Acústica arquitetônica. Brasília: Thesaurus, 2010.

ESTADO DO RIO GRANDE DO SUL. Tribunal de Justiça. Recurso Crime no 71005569488, da Turma Recursal do Tribunal de Justiça do Estado de Rio Grande do Sul, RS, 7 mar. 2016. $\quad$ Disponível em: http://www.tjrs.jus.br/busca/search?q=N\%C2\%BA+71005569488+\&proxystylesheet=tjrs_ind ex\&client $=$ tjrs_index \&filter $=0 \&$ getfields $=* \& a b a=$ juris $\&$ entsp $=$ a__politica-site $\&$ $w c=200 \& w c \_m c=1 \& o e=U T F-8 \& i e=U T F-8 \& u d=1 \& 1 r=1$ lang_pt $\&$ sort $=$ date $\% 3 A D \% 3 \mathrm{~A}$ S\%3Ad1\&as_qj=N\%C2\%BA+71005569488+\%28N\%C2\%BA+CNJ\%3A+002805021.2015.8.21.9000\%29\&site=ementario\&as_epq $=\&$ as_oq $=\&$ as_eq $=\&$ partialfields $=0 \% 3 \mathrm{Acru}$ z.o\%3Aalta\&as_q=+\#main_res_juris Acesso em: 11 mai. 2016.

ESTADO DO RIO GRANDE DO SUL. Tribunal de Justiça. Recurso Crime no 71005207204, da Turma Recursal do Tribunal de Justiça do Estado de Rio Grande do Sul, RS, 262 jan. 2015.2 Disponível http://www.tjrs.jus.br/busca/search?q=71005207204+\&proxystylesheet=tjrs_index\&client=tjr s_index \&filter $=0 \&$ getfields $=* \& a b a=j u r i s \& e n t s p=a \_$politica-site $\& w c=200 \& w c$ $\mathrm{mc}=1 \&$ oe $=\mathrm{UTF}-8 \& \mathrm{ie}=\mathrm{UTF} \& \mathrm{ud}=1 \& \mathrm{lr}=$ lang_pt\&sort=date $\% 3 \mathrm{AD} \% 3 \mathrm{AS} \% 3 \mathrm{Ad} 1 \&$ as_q $\mathrm{j}=\mathrm{N} \% \mathrm{C} 2 \% \mathrm{BA}+71005569488+\&$ site $=$ ementario\&as_epq=\&as_oq=\&as_eq=\&partialfields $=0$ \%3Acruz.o\%3Aalta\&as_q=+\#main_res_juris. Acesso em: 12 mai. 2016. 
ESTADO DO RIO GRANDE DO SUL. Tribunal de Justiça. Recurso Crime no 70056708431, da Quarta Câmara do Tribunal do Estado de Rio Grande do Sul, RS, 17 out. 2013.

Disponível

em: http://www.tjrs.jus.br/busca/search?q=70056708431+\&proxystylesheet=tjrs_index\&client=tjr $\mathrm{s} \_$index\&filter $=0 \&$ getfields $=* \& a b a=j u r i s \& e n t s p=a \_$politica-site $\& w c=200 \& w c$ _mc $=1 \&$ oe $=$ UTF-8\&ie $=$ UTF\&ud=1\&lr=lang_pt\&sort=date\%3AD\%3AS\%3Ad1\&as_ qj=71005207204+\&site=ementario\&as_epq=\&as_oq=\&as_eq=\&as_q=+\#main_res_juris. Acesso em: 12 mai. 2016.

ESTADO DO RIO GRANDE DO SUL. Tribunal de Justiça. Recurso Crime $\mathbf{n}^{\mathbf{0}}$ 71005565510, da Turma Recursal do Tribunal de Justiça do Estado de Rio Grande do Sul, RS, 09 mai. 2016. Disponível em: http://www.tjrs.jus.br/busca/search?q=71005565510+\&proxystylesheet=tjrs_index\&client=tjr s_index \&filter $=0 \&$ getfields $=* \& a b a=$ juris $\&$ entsp $=$ a_politica-site $\& w c=200 \& w c$ $\mathrm{mc}=1 \&$ oe $=\mathrm{UTF}-8 \& \mathrm{ie}=\mathrm{UTF} \& \mathrm{ud}=1 \& \mathrm{lr}=$ lang_pt\&sort=date\%3AD\%3AS\%3Ad1\&as_ $\mathrm{qj}=70056708431+\&$ site=ementario\&as_epq=\&as_oq=\&as_eq=\&as_q=+\#main_res_juris. Acesso em: 08 jun. 2016.

ESTADO DO RIO GRANDE DO SUL. Tribunal de Justiça. Recurso Crime $\mathbf{n}^{\mathbf{0}}$ 70033430190, da Quarta Câmara do Tribunal do Estado de Rio Grande do Sul, RS, 17 dez. 2009. Disponível em: http://www.tjrs.jus.br/busca/search?q=70033430190\&proxystylesheet=tjrs_index\&client=tjrs _index\&filter $=0 \&$ getfields $=* \& a b a=j u r i s \& e n t s p=a \_p o l i t i c a-s i t e \& w c=200 \& w c \_m$ $\mathrm{c}=1 \&$ oe $=\mathrm{UTF}-8 \& \mathrm{ie}=\mathrm{UTF} \& \mathrm{ud}=1 \& \mathrm{lr}=$ lang_pt\&sort=date $\% 3 \mathrm{AD} \% 3 \mathrm{AS} \% 3 \mathrm{Ad} 1 \&$ as_qj $=71005565510+\&$ site=ementario\&as_epq=\&as_oq=\&as_eq=\&as_q=+\#main_res_juris. Acesso em: 12 mai. 2016.

ESTADO DO RIO GRANDE DO SUL. Tribunal de Justiça. Recurso Crime $\mathbf{n}^{\mathbf{0}}$ 71002322238, da Quarta Câmara do Tribunal do Estado de Rio Grande do Sul, RS, 30 nov. 2009.

Disponível

em: http://www.tjrs.jus.br/busca/search?q=71002322238\&proxystylesheet=tjrs_index\&client=tjrs _index\&filter $=0 \&$ getfields $=* \& a b a=j u r i s \& e n t s p=a \_$politica-site $\& w c=200 \& w c$ $\mathrm{mc}=1 \& o e=U T F-8 \& \mathrm{ie}=\mathrm{UTF} \& \mathrm{ud}=1 \& 1 \mathrm{r}=$ lang_pt $\&$ sort=date $\% 3 \mathrm{AD} \% 3 \mathrm{AS} \% 3 \mathrm{Ad} 1 \&$ as_qj $=71003088200 \&$ site $=$ ementario\&as_epq=\&as_oq=\&as_eq=\&as_q=+\#main_res_juris. Acesso em: 12 mai. 2016.

FELLENBERG, Gunter. Introdução aos problemas da poluição ambiental. São Paulo: EPU, 2012.

FERRAJOLI, Luigi. Direito e razão. Teoria do garantismo penal. São Paulo: Revista dos Tribunais, 2010.

IZQUIERDO, Ivan. Silêncio, Por favor!. Tradução de Editora Unissinos. São Leopoldo: Editora Unissinos, 2002.

LEITE, José Rubens Morato. Dano Ambiental: do individual ao coletivo extrapatrimonial. São Paulo: Revista dos Tribunais, 2000. 
LUNELLI, Carlos Alberto. POLETTO, Leonardo Augusto. O Direito fundamental da proteção do meio ambiente no ordenamento jurídico brasileiro e o protagonismo do direito em matéria ambiental. LUNELLI, Carlos Alberto (coord). Direito, ambiente e políticas públicas. Curitiba: Juruá, 2011.

MARIN, Jefeson Dytz. Relativização da coisa julgada e inefetividade da jurisdição. Curitiba: Juruá, 2015.

RECH, Adir Ubaldo. Zoneamento ambiental como plataforma de planejamento da sustentabilidade. Caxias do Sul: Educs. 2012.

SILVA, José Afonso da. Curso de direito constitucional positivo. São Paulo: Malheiros, 2012

SILVA, Ovídio Araújo Baptista da. Epistemologia das ciências culturais. Porto Alegre: Verbo Jurídico. 2009.

SIRVINSKAS, Luís Paulo. Manual de direito ambiental. São Paulo: Saraiva. 2009.

VEIGA, José Eli da. Desenvolvimento sustentável: o desafio do século XXI. Rio de Janeiro: Garamond. 2000. 